\title{
Testicular Mixed Choriocarcinoma and Embryonal Carcinoma
}

National Cancer Institute

\section{Source}

National Cancer Institute. Testicular Mixed Choriocarcinoma and Embryonal Carcinoma. NCl Thesaurus. Code C6348.

A malignant mixed germ cell tumor that arises from the testis and is characterized by the presence of choriocarcinoma and embryonal carcinoma morphologic components. 